\title{
A Study on Need for External Help for Tobacco Users in Madurai East Block
}

\author{
P. Ramasamy \\ Former Asst. Professor \& Research Co-ordinator, \\ Department of Social Work, Madurai Institute of Social Sciences, \\ Madurai, India
}

\begin{abstract}
:
The study focuses on need for external help associated with tobacco use. Tobacco use is usually initiated during adolescence and it continues till the end of life by most people. Chewing gum that provides a slow release of nicotine into the bloodstream, and electronic cigarettes that use water vapour for smoke are all increasingly popular methods of getting nicotine. The initiation of tobacco use in any form is related to personal factors like age, sex, social class, education, income, etc. The present study deals with the need for external help in Madurai East Block. The study is a descriptive study which was conducted in 6 villages covering 841 tobacco users in Madurai East Block. The major findings indicate that $56.2 \%$ of them wanted to have counseling and rehabilitation services from external sources. The desire for getting help from external resource denotes that people want to get away from the habit of using of tobacco products and their ill effects.
\end{abstract}

Key words: External Help, Tobacco use

Acknowledgement: This article is a part of the UGC sponsored major research project titled An Action research project towards creating a tobacco free zone.

\section{Introduction:}

Tobacco is an addictive product which is used in many forms like raw tobacco, snuff, panparak, kutka, cigarette, bidi and others. Generally the habit of tobacco use is initiated at young age ie. Among children and adolescents ( Peta et.al 1994) and continues till the end of life by most people. The nicotine in tobacco leads to addiction among tobacco users. Therefore, trying to quit tobacco use often requires external help for leaving the habit. Chewing gum that provides a slow release of nicotine into the bloodstream, and electronic cigarettes that use water vapour for smoke are all increasingly popular methods of getting nicotine; however, the ultimate goal is to remove the dependency on nicotine. Therefore, tobacco de-addiction treatment is often necessary.The present study tries to investigate about the type of help expected from the external sources in order to give up the habit of using tobacco products.

\section{Methodology:}

Descriptive research design has been adopted for this study. Among 39 villages in Madurai East Block, 6 villages were selected randomly using lottery method. The primary data were collected from the adolescents, middle age and old age people who were available between 9am and $6 \mathrm{pm}$ in 6 villages .Each respondent was interviewed in a congenial atmosphere by using an interview schedule. Thus the study population comprised of 841 people (648 male and 193 female). Data were analyzed using frequency and percentage.

\section{Results and Discussions:}

The results of the analyzed data are tabulated in Table 1 and discussed below:

In order to understand the felt needs of the people residing in the operational area of the research study, they were asked to tell about their desire regarding the help that they wanted to get rid the habit. As many as $44.1 \%$ of the respondents wanted help for getting awareness while $56.2 \%$ of them wanted to have counseling and rehabilitation services. As much as $41.5 \%$ and $44.1 \%$ of the respondents respectively wanted help for psychological treatment and assistance during recovery process. The desire for getting help 
mentioned above denotes that people want to get away from the habit of use of tobacco products and their ill effects.

Table No: 1

Type of help that the tobacco users expected from external sources

\begin{tabular}{|c|c|c|c|c|c|c|c|}
\hline \multirow{2}{*}{ S.No } & \multirow{2}{*}{$\begin{array}{c}\text { Type of help expected } \\
\text { from external sources }\end{array}$} & \multicolumn{4}{|c|}{ Sex } & \multicolumn{2}{|c|}{} \\
\cline { 3 - 6 } & \multirow{2}{*}{1} & $\mathbf{2}$ & $\mathbf{2}$ & $\mathbf{N}$ & $\mathbf{\%}$ & $\mathbf{N}$ & $\mathbf{2}$ \\
\cline { 3 - 7 } & Awareness & 305 & 36.3 & 66 & 7.8 & 371 & 44.1 \\
\hline 2 & Counselling/Rehabilitation & 378 & 44.9 & 95 & 11.3 & 473 & 56.2 \\
\hline 3 & Psychological Treatment & 275 & 32.7 & 74 & 8.8 & 349 & 41.5 \\
\hline 4 & Recovery Process & 305 & 36.3 & 66 & 7.8 & 371 & 44.1 \\
\hline & Total & 648 & 77.1 & 193 & 22.9 & 841 & 100 \\
\hline
\end{tabular}

Tobacco users in the long run become addicts to the habit as nicotine - a component of tobacco - is an addictive product. Addiction is a state of dependency and those who are addicted face difficulties in getting away from the habit. So there is a need for external help in the form of treatment, counseling etc.

There are various forms of treatment programmes available (American Addiction Centre 2019). Sometimes Professional help is needed to quit the habit of tobacco use. Inpatient and outpatient rehabilitation programmers are available. The inpatient phase will usually consist of tobacco de-toxification and during the recovery; no tobacco or nicotine is allowed. After the withdrawal phase is complete, the patient will undergo counselling. These therapy sessions provide opportunity to the patient and therapist to discuss healthy stress relief strategies for decreasing dependence on tobacco.

In Columbia, in all 50 states and the districts some type of free, telephone-based program is offered that links callers with trained counsellors. These specialists help the tobacco users to plan a quit method considering the uniqueness of each client. People who use telephone counselling have twice the success rate in quitting smoking as those who don't get this type of help. (The American Cancer Society Medical and editorial content team, January 2, 2017).

A combination of methods including medicines, local classes, self-help brochures,and/or a network of family and friends work well in de-addiction. Help from a counsellor can keep quitters from making many common mistakes.

The effectiveness of phone-based services has led to the development of many web-based quit aids and mobile apps. These offer another easy-to-use support resource to people trying to quit. Most former smokers quit without using one of the treatments that scientific research has shown can work (Centre for disease control and prevention 2017) suggested by Fiore et al 2017 However, the following treatments are proven to be effective for smokers who want help to quit:

- $\quad$ Brief help by a doctor (such as when a doctor takes 10 minutes or less to give a patient advice and assistance about quitting)

- Individual, group, or telephone counseling

- Behavioral therapies (such as training in problem solving)

- Treatments with more person-to-person contact and more intensity (such as more or longer counseling sessions)

- Programs to deliver treatments using mobile phones

\section{Conclusion}

Tobacco smoke contains a deadly mix of more than 7,000 chemcials. Among them hundreds are harmful and about 70 can cause cancer. Smoking increases the risk for serious health problems, diseases, and death. People who stop smoking greatly reduce their risk for disease and early death. Although the health benefits are greater for people who stop at earlier ages, there are benefits at any age.

The report of Centre for Disease Control Prevention (2015) reveals that $\boldsymbol{a}$ mong all the U.S. adult cigarette smokers, nearly 7 out of every 10 (68.0\%) reported in 2015 that they wanted to quit completely. Percentage of adult daily cigarette 
smokers who stopped smoking for more than 1 day in 2015 because they were trying to quit is as follows

- $\quad$ More than 5 out of $10(55.4 \%)$ of all adult smokers

- $\quad$ Nearly 7 out of $10(66.7 \%)$ smokers aged 18-24 years

- $\quad$ Nearly 6 out of $10(59.8 \%)$ smokers aged 25-44 years

- $\quad$ More than 4 out of $10(49.6 \%)$ smokers aged 45-64 years

- $\quad$ About 4 out of $10(47.2 \%)$ smokers aged 65 years or older

The above said results show that most individuals have an inner feeling of getting rid of the addiction to tobacco. The present study reveals the fact that the desire for getting help is positive sign to get away from the habit of use of tobacco products and their ill effects. So, Government should take necessary steps to provide needed interventions to help people to quit from these practices. NGOs, Local Medical Practitioners and volunteers can play an additional role in helping people to quit tobacco use and prevent the incidence of tobacco use.

\section{References:}

[1] Centers for Disease Control and Prevention. Quitting Smoking Among Adults-United
States, 2000-2015. Morbidity and Mortality Weekly Report 2017;65(52):1457-64 [accessed 2017 Jan 24].

[2] Centers for Disease Control and Prevention. Youth Risk Behavior Surveillance-United States, 2015. Morbidity and Mortality Weekly Report [serial online] 2016;66(SS-6):1-174 [accessed 2017 Jan 24].

[3] Fiore MC, Jaén CR, Baker TB, et al. Treating Tobacco Use and Dependence: 2008 UpdateClinical Practice Guidelines. Rockville (MD): U.S. Department of Health and Human Services, Public Health Service, Agency for Healthcare Research and Quality, 2008 [accessed 2017 Jan 24].

[4] Peto R, Lopez AD, Boreham J, Thun M, Heath CJ.Mortality from smoking in developed countries 1950-2000: indirect estimates from national vital statistics. Oxford University Press, $1994 . \quad$ (2004 update on www.ctsu.ox.ac.uk)

[5] Project Know; American Addiction Centre. Resources for those looking to quit using tobacco: Treatment programmes available 2019.

[6] The American Cancer Society Medical and editorial content team; Stay Healthy : Stay away of tobacco: Quit tobacco programmes: Telephone based help to stop using tobacco. Last Medical Review January 12, 2017. 